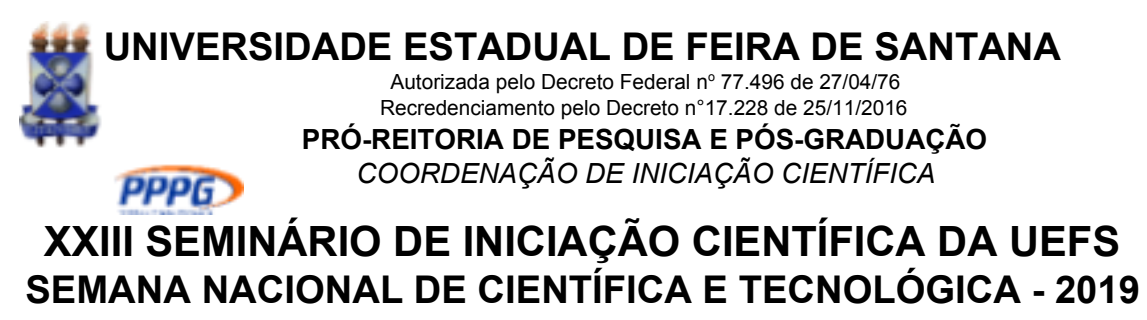

\title{
Melhoramento da Geração de Malhas de Polígonos do Módulo de Scanner 3D
}

\author{
Murilo Cruz Lopes ${ }^{1}$; Claudio Eduardo Goes ${ }^{2}$ \\ 1. Bolsista Fabesb, Graduando em Engenharia de Computação, Universidade Estadual de Feira de \\ Santana, e-mail: cruzlopesmurilo@gmail.com \\ 2. Professor, Departamento de Ciências Exatas, Universidade Estadual de Feira de Santana, e-mail: \\ cegoes@ecomp.uefs.br
}

PALAVRAS-CHAVE: digitalização; tridimensional; robôs, visão, computacional, laser.

\section{INTRODUÇÃOO}

A digitalização tridimensional a laser (3D Laser Scanning) é uma tecnologia que permite a obtenção de nuvens de pontos a partir da varredura das superfícies de objetos por feixes de luz (GROETELAARS e AMORIM, 2011). Essa tecnologia tem sido empregada na digitalização de objetos como por exemplo: na área de ortodontia e na recuperação de patrimônios culturais (WISPEL et. al, 2017). Tem-se tornado comum lojas virtuais compartilharem modelos tridimensionais, assim como fabricantes de várias áreas, a fim de facilitar e atender necessidades diversas dos clientes WINSCH \& SANTOS (2014), LOPES, et al (2019).

Este trabalho integra o projeto colônia de robôs que visa o desenvolvimento de robôs autônomos para busca e inspeção. Assim, esse trabalho visa colaborar na construção de um módulo de digitalização de peças que podem ser aplicadas em robôs dentro do projeto. As peças digitalizadas podem ser utilizadas posteriormente para replicação de novas, principalmente com o avanço de impressoras 3D. A utilização da impressão 3D torna mais barata a obtenção de peças para serem utilizadas em robôs, como por exemplo a base de um robô de quatro rodas Straub et al. (2014), Campbell et al. (2011), Lopes, et al. (2019).

\section{MATERIAL E MÉTODOS OU METODOLOGIA}

Para a realização da digitalização de um objeto é necessário seguir algumas etapas. O fluxograma da Figura 1 mostra as etapas seguidas, onde se 
inicia através da rotação da base giratória, onde o objeto fica posicionado e é rotacionado, utilizando um motor de passo e um arduino para o controle do motor e que é programado utilizando a linguagem $\mathrm{C++}$. A etapa de Capturar Frame engloba a etapa responsável por capturar os frames que são utilizadas nas etapas de Segmentar linha do laser e Esqueletização, onde depois os pontos da linha do laser segmentado tem suas coordenadas calculadas na etapa de triangulação e os dados são salvos na etapa de Salvar Coordenadas em Arquivos. Esse processo é repetido 1600 vezes, pois é quantidade de passos que o motor deve dar para rotacionar 360 graus.

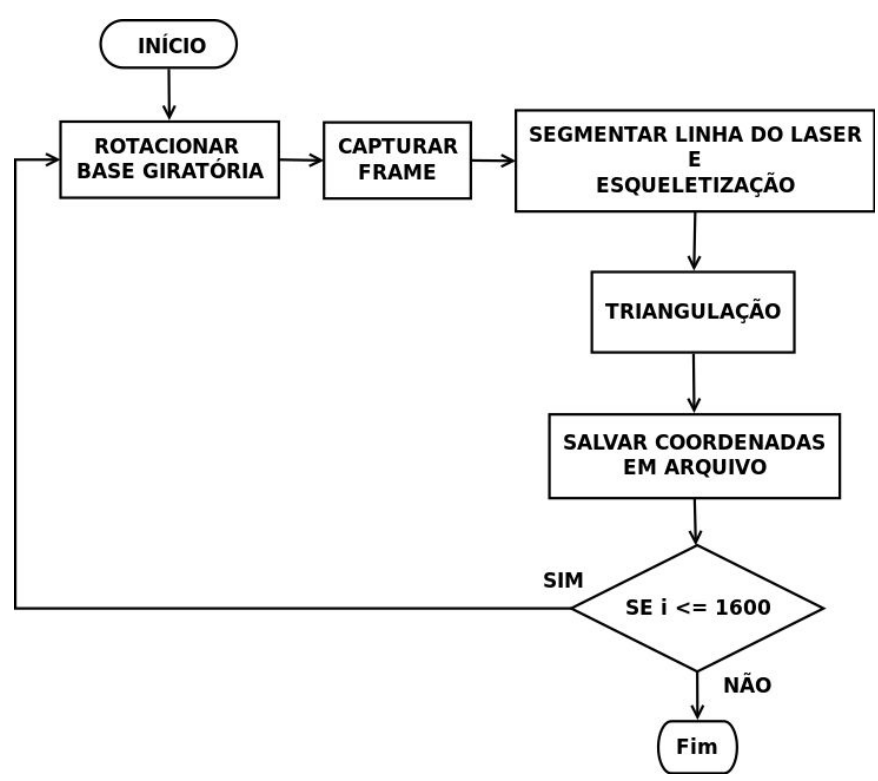

Figura 1: Fluxograma de funcionamento do digitalizador. Fonte: Próprio autor.

Para realizar a segmentação da linha do laser foi utilizada a técnica de diferença de imagens. Essa técnica consiste em fazer o cálculo da subtração de uma imagem por outra, ou seja, $H(x, y)=F(x, y)-G(x, y)$, onde a imagem $H$ recebe $o$ resultado da subtração da imagem $F$ pela imagem $G$. Assim, captura-se um frame do modelo com a linha do laser incidindo sobre ele e em seguida outro frame com a linha do laser não incidindo sobre o objeto. A Figura 2 (a), 2 (b) mostram os frames com ou sem o laser a Figura 2 (c) mostra 0 resultado da diferença entre as imagens.
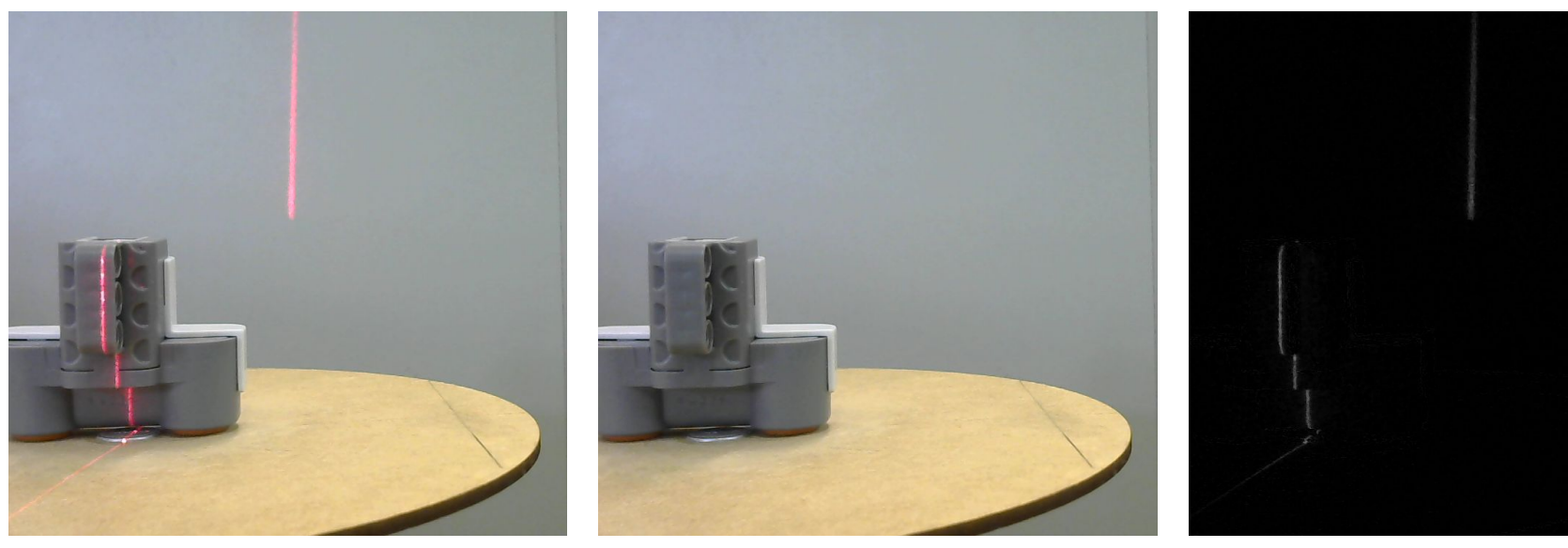
Figura 2: a) Linha do laser incidindo sobre a imagem $F(x, y)$. b) Modelo sem a luz do laser incidir na imagem $G(x, y)$. c) Imagem $H(x, y)$ resultante da diferença entre as imagens $F(x . y) e$ $G(x, y)$.

Os resultados abrangem dois pontos, o primeiro é a análise de acurácia das medidas de ground truth da linha do laser e os resultados da digitalização através da análise de malhas a partir de dois algoritmos: Poisson Surface Reconstruction e Ball Pivoting. A Tabela 1 abaixo mostra os resultados através 31 imagens utilizada para a medida do ground truth de um modo geral.

Tabela 1 - Resultado de um conjunto de 31 imagens

\begin{tabular}{|l|c|c|}
\hline Resultados & $\begin{array}{c}\text { Predição do modelo: } \\
\text { positivo }\end{array}$ & $\begin{array}{c}\text { Predição do modelo: } \\
\text { negativo }\end{array}$ \\
\hline Verdade: positiva & $97,88 \%$ & $2,12 \%$ \\
\hline Verdade: negativa & $0,6385 \%$ & $99,36 \%$ \\
\hline
\end{tabular}

As Figuras abaixo mostram os resultados obtidos para a análise de malhas para uma roda de robô da Lego:

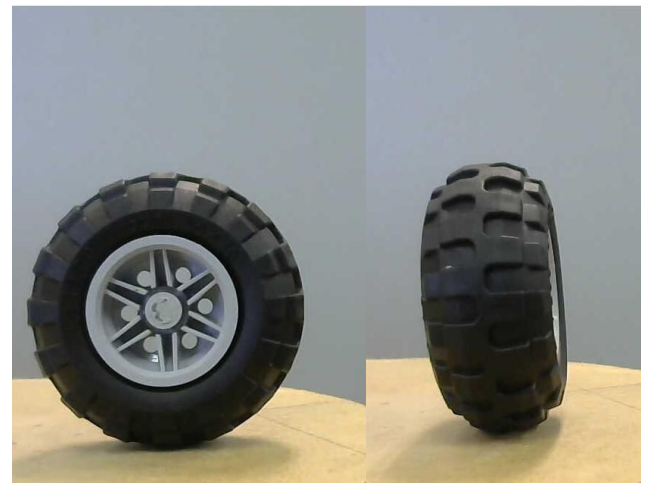

Figura 2 - Rodas legos utilizada no teste

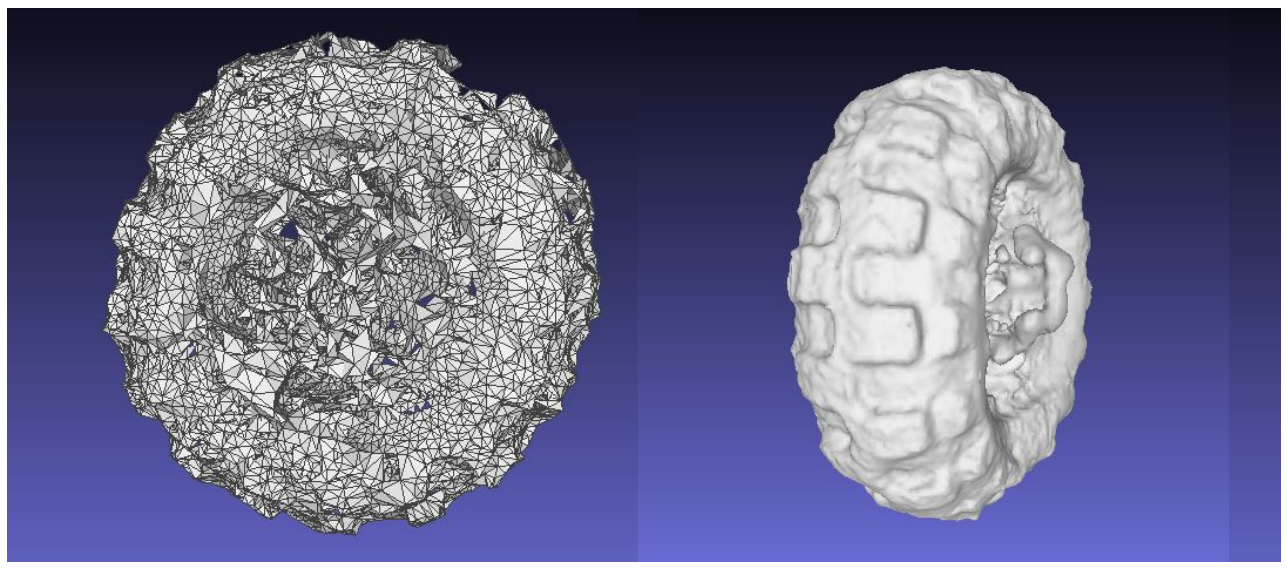

Figura 3 - Resultado utilizando o Poisson Surface Reconstruction da roda Lego

\section{CONCLUSÃO}


Este artigo abordou o desenvolvimento de um digitalizador que consegue fazer o controle de uma base giratória, laser, até a etapa de triangulação para a obtenção das coordenadas reais do objeto. Como foco principal foi a realização de uma melhoria através de uma nova técnica de segmentação utilizando diferença de imagens e aplicação do método de segmentação de Otsu para a detecção do laser. Esse método permitiu uma melhora na segmentação em relação ao método anterior, que utilizava a intensidade do laser, como pode ser visto que o método por diferença de imagens elimina o problema da luminosidade sobre o objeto. Esse trabalho também comparou o uso de dois algoritmos de reconstrução de superfície, Poisson Surface Reconstruction e o Ball Pivoting.

\section{REFERÊNCIAS}

GROETELAARS, N. J.; AMORIM, A. L. Tecnologia 3D Laser Scanning: características, processos e ferramentas para manipulação de nuvens de pontos 3D Laser Scanning Technology: characteristics, processes and point cloud tools. XV Congreso SIGRADI, 2011.

WISPEL, W.; MACHADO, R.; LEGG, A. P.; BAYER, F. M. Um scanner 3D de baixo custo. XXXV Simpósio brasileiro de telecomunicações e processamento de sinais. São Pedro, São Paulo, 2017

WINSCH, G. A; SANTOS, P. H. S, Desenvolvimento de um escâner tridimensional por triangulação baseado em sistema ótico e feixe de laser. Dissertação (Bacharelado em Engenharia Eletrônica). Universidade Tecnológica Federal do Paraná, Toledo, Paraná, 2004.

HASANUDDIN, M. O.; PERMANA, G. E.; AKBAR, I.; WURYANDARI, A. I. 3D Scanner for Orthodontic Using Triangulation Method. The 5th International Conference on Electrical Engineering and Informatics, 2015.

SANSONI, G.; TREBESCHI, M.; DOCCHIO, F. State-of-The-Art and Applications of 3D Imaging Sensors in Industry, Cultural Heritage, Medicine, and Criminal Investigation. Sensors, 2009

STRAUB, J. and KERLIN, S. (2014). Development of a large, low-cost, instant $3 D$ scanner.

pages 76-95. Technologies

LOPES, M. C, GOES, C. E; Módulo de Digitalização 3D de Peças para o Projeto Colônia de Robôs. XIX Escola Regional de Computação Bahia, Alagoas e Sergipe. 2019 (Aceito para publicação) 